\title{
Pengendali Lampu LED Matrix Headlamp pada Kendaraan Bermotor
}

\author{
Jatmiko Tri Waluyo ${ }^{1}$, Nuryono Satya Widodo ${ }^{2}$ \\ ${ }^{1}$ Mahasiswa Program Studi Teknik Elektro, Universitas Ahmad Dahlan, Indonesia \\ ${ }^{2}$ Dosen Program Studi Teknik Elektro, Universitas Ahmad Dahlan, Indonesia
}

\section{INFORMASI ARTIKEL}

\section{Riwayat Artikel:}

Dikirimkan 15 Juni 2019,

Direvisi 25 Juli 2019,

Diterima 12 Agustus 2019.

\section{Kata Kunci:}

LED,

Sensor BH1750,

Arduino uno,

Lampu Kendaraan.

\begin{abstract}
ABSTRAK
Penelitian ini mengusulkan tentang desain Headlamp lampu kendaraan yang dapat meredup berdasarkan pada data lampu kendaraan lawan. Pengolah data menggunakan Arduino uno dan menggunakan sensor BH1750 untuk membaca intensitas cahaya. Lampu Headlamp terdiri dari 3 baris LED yang terdiri dari 4 buah LED setiap baris. Lalu juga terdapat 1 buah lampu LED utama di kanan dan kiri. Berdasarkan pengujian dapat diketahui bahwa lampu LED dapat bekerja dengan baik yaitu dapat meredup dari mulai LED pada baris pertama dan kedua sesuai dengan intensitas cahaya. Perbandingan pengukuran menggunakan perangkat lightmeter menunjukkan bahwa perangkat memiliki nilai error $-53,925$ dan standar deviasi 51,6110126 yang menunjukkan bahwa desain perangkat masih belum mendapatkan hasil yang baik.
\end{abstract}

This work is licensed under a Creative Commons Attribution-Share Alike 4.0

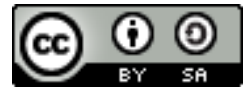

\section{Penulis Korespondensi: \\ Jatmiko Tri Waluyo, \\ Program Studi Teknik Elektro, Universitas Ahmad Dahlan, \\ Kampus 4 UAD, Jln. Ring Road Selatan, Tamanan, Banguntapan, Bantul, Yogyakarta, Indonesia. \\ Surel: Jatmikomiko14@gmail.com}

\section{PENDAHULUAN}

Pada kemajuan zaman ini beberapa kemajuan yang didukung dengan teknologi yang semakin canggih. Susunan sebuah alat yang dapat memberikan respons pengaturan pencahayaan kendaraan saat malam hari, atau dapat menyesuaikan dengan keadaan sekeliling kendaraan pada saat kendaraan berada dalam kota ataupun pedesaan serta hutan [1]. Berdasarkan aturan tersebut (Pasal 107 Undang - Undang No. 22 Tahun 2009 tentang lalu lintas dan angkutan jalan) maka selain lampu kendaraan yang dapat menyesuaikan keadaan sekitar pada malam hari juga tidak lupa diberikan lampu pencahayaan yang akan terus hidup pada siang hari [2]. Penggunaan teknologi mikrokontroler pada dunia industri dan jasa telah banyak digunakan. Seperti keperluan quality control, packing produk, perakitan dan lain-lain [3]. Mikrokontroler berfungsi sebagai pengatur kerja alat agar dapat bekerja secara sistematis [4].

Proses otomasi sistem kendali LED Matrix Headlamp pada kendaraan bermotor tidak akan lepas dari penggunaan perangkat elektronik, seperti halnya penggunaan berbagai macam sensor dan komponen penting lainnya [5]. Sensor ultrasonik BH1750 adalah sebuah sensor yang berfungsi untuk mengubah nilai intensitas cahaya yang diterima sensor dan kemudian akan diolah sebagai pembacaan jarak titik letak sensor BH1750 dengan rangsangan cahayanya [6]. Kemudian dengan diketahuinya nilai jarak tersebut akan mengakibatkan berisan-barisan LED Matrix Headlamp yang terpasang dalam kendaraan akan mematikannya [7]. Tanpa mematikan lampu utama pada kendaraan tersebut, dikarenakan aturan yang telah disebutkan dalam Undangundang lalu lintas [8]. Arduino Uno merupakan sebagai penyimpan serta pengaturan input data yang nantinya akan dikeluarkan sesuai dengan program yang kita masukan dalam Arduino Uno [9]. 
Tujuan dari penelitian ini adalah untuk membuat prototipe atau miniatur sistem LED Matrix headlamp pada kendaraan bermotor untuk menampilkan inovasi baru dengan mengembangkan penelitian-penelitian sebelumnya. Arduino adalah platform pembuatan prototipe elektronik yang bersifat open source hardware yang berdasarkan pada perangkat keras dan perangkat lunak yang fleksibel dan mudah digunakan [10]. Memberikan kemudahan dalam pengendara kendaraan bermotor di segala medan yang berbeda-beda kondisinya.

\section{METODE PENELITIAN}

\subsection{DESAIN SISTEM}

Dalam penelitian ini dibuat sistem LED Matrix Headlamp yang bekerja menggunakan sensor BH1750, untuk mengetahui berapa jarak kendaraan yang berada di bagian depan. Selanjutnya pembacaan jarak, yang kemudian akan masuk ke pemrosesan Arduino Uno kemudian pada Arduino Uno melakukan pemrosesan untuk mematikan LED yang berdasarkan masukan yang diberikan pada pemrograman dengan acuan jarak obyek atau benda (mobil) yang berada di bagian depan. Setelah pemrosesan berakhir tindakan mematikan/meredupkan LED akan dilakukan berdasarkan perintah atau program yang ada pada Arduino. Perancangan sistem dipresentasikan dalam bentuk diagram blok yang terlihat seperti pada Gambar 1 .

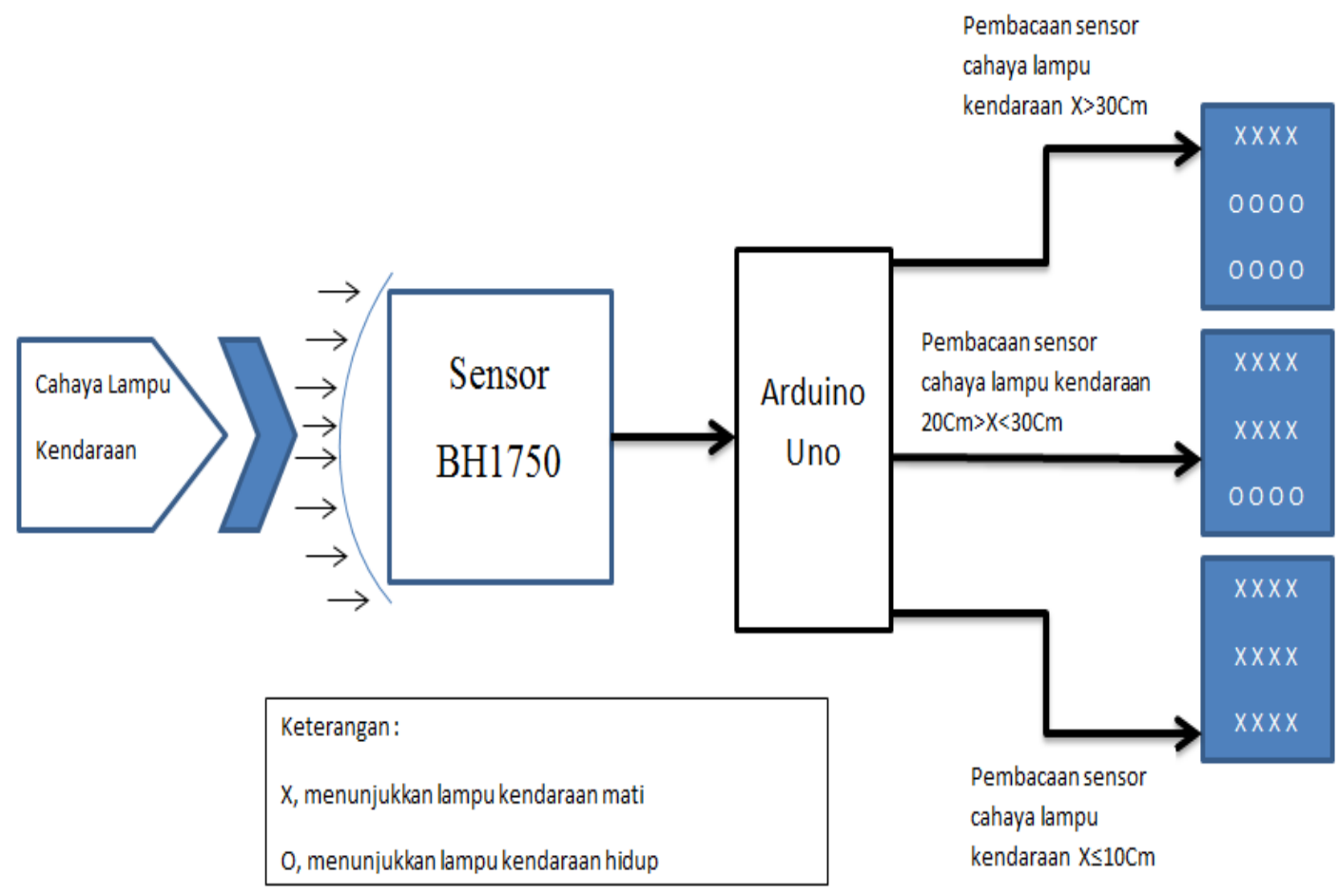

Gambar 1. Diagram blok perancangan hardware

Perakitan perangkat keras merupakan proses dalam menghubungkan semua perangkat. Penjelasan berdasarkan Gambar 1 adalah sebagai berikut. Cahaya dari kendaraan yang berlawanan arah akan diterima sensor BH1750 sebagai masukan yang kemudian akan masuk ke dalam Arduino Uno untuk diproses berdasarkan program yang telah dimasukkan. Keluaran akan berupa pilihan tiga aksi LED yang ditentukan berdasarkan nilai kecerahan cahaya dari kendaraan berada pada lawan arah, sehingga dapat membaca nilai sensor sampai memicu kinerja nilai keluaran.

Rangkaian keseluruhan sistem dapat dilihat pada Gambar 2. Sensor BH1750 diletakkan pada bagian depan mobil. Di bagian depan mobil juga terdapat 12 buah LED yang dapat menyala dan meredup. Lalu terdapat 2 buah LED sebagai lampu LED utama yang terus menyala. 


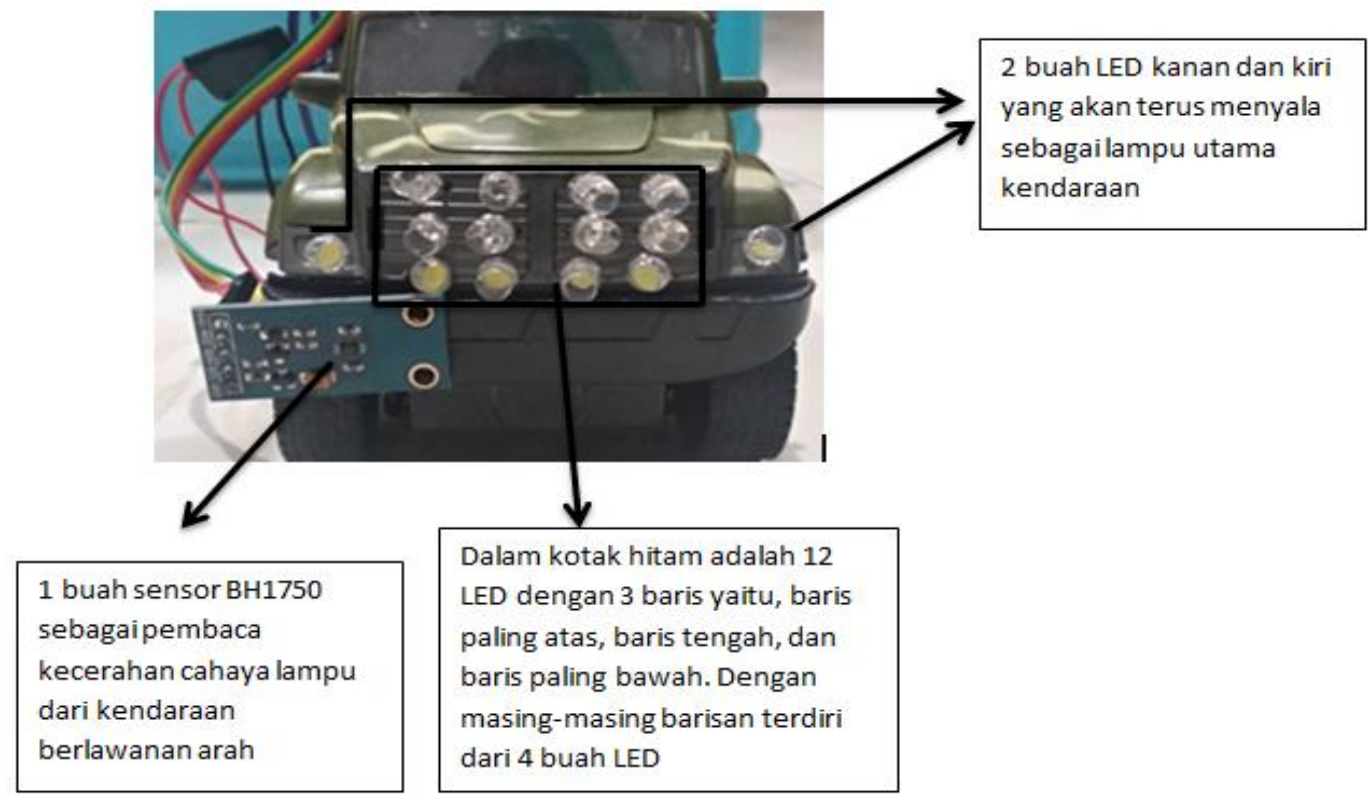

Gambar 2. Rangkaian keseluruhan sistem

Pin yang digunakan pada Arduino dengan komponen ditunjukkan pada Gambar 3 berikut ini.

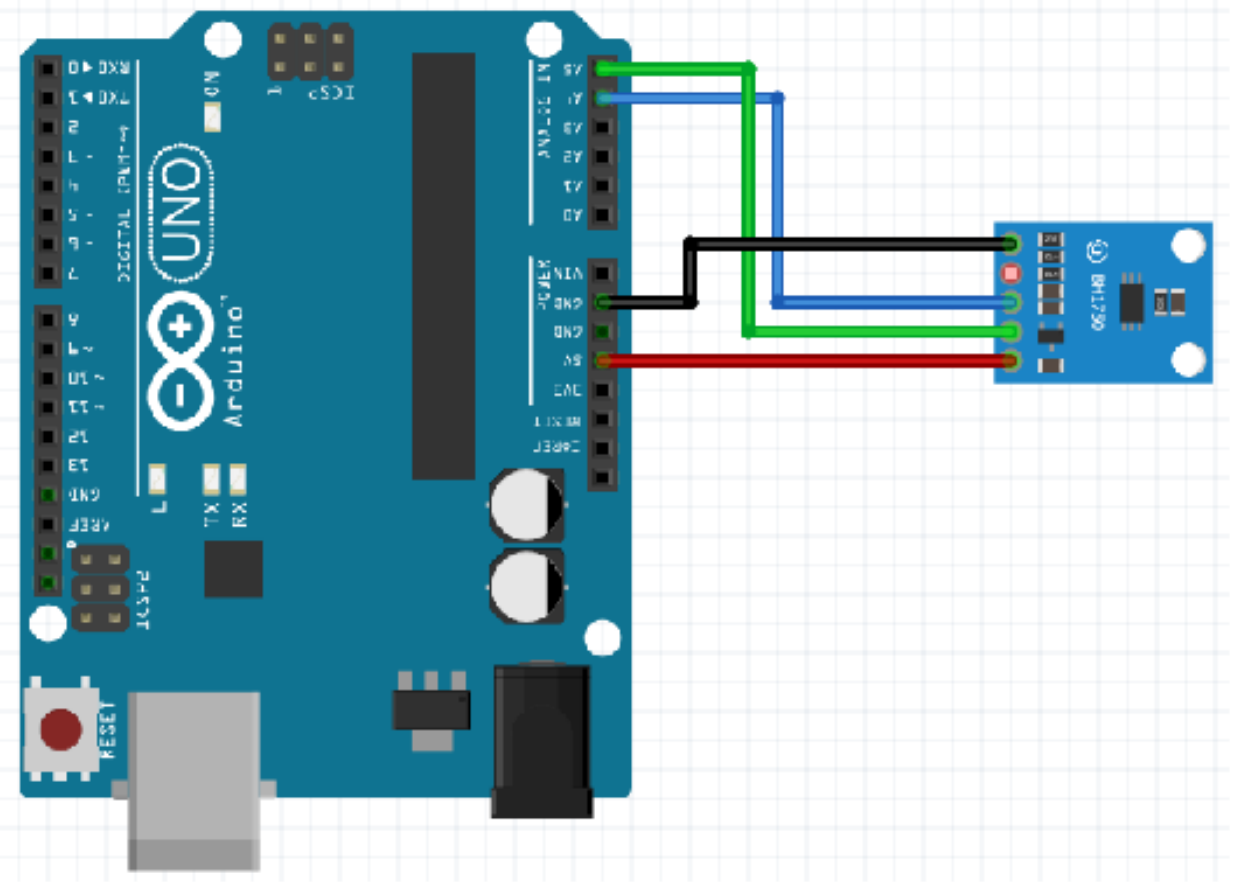

Gambar 3. Pin Arduino dengan komponen

Penjelasan Gambar 3 adalah sebagai berikut. Pada rangkaian sensor BH1750, PIN GND dihubungkan ke PORT GND (hitam), PIN SDA dihubungkan ke PORT A4 (biru), PIN SCL dihubungkan ke PORT A5 (hijau), dan PIN VCC dihubungkan ke PORT 5V (warna merah). Sensor BH1750 merupakan sensor yang menggunakan komunikasi I2C pada PIN SDA dan SCL yang tersambung pada PIN A4 dan A5 pada Arduino Uno. Berdasarkan rangkaian di atas untuk menguji sistem kerja sensor BH1750 dilakukan dengan pemrograman pada Arduino IDE. Perancangan konstruksi alat dibuat sedemikian rupa agar sistem berjalan sesuai dengan tujuan. Perancangan pengujian alat ditunjukkan pada Gambar 4. 


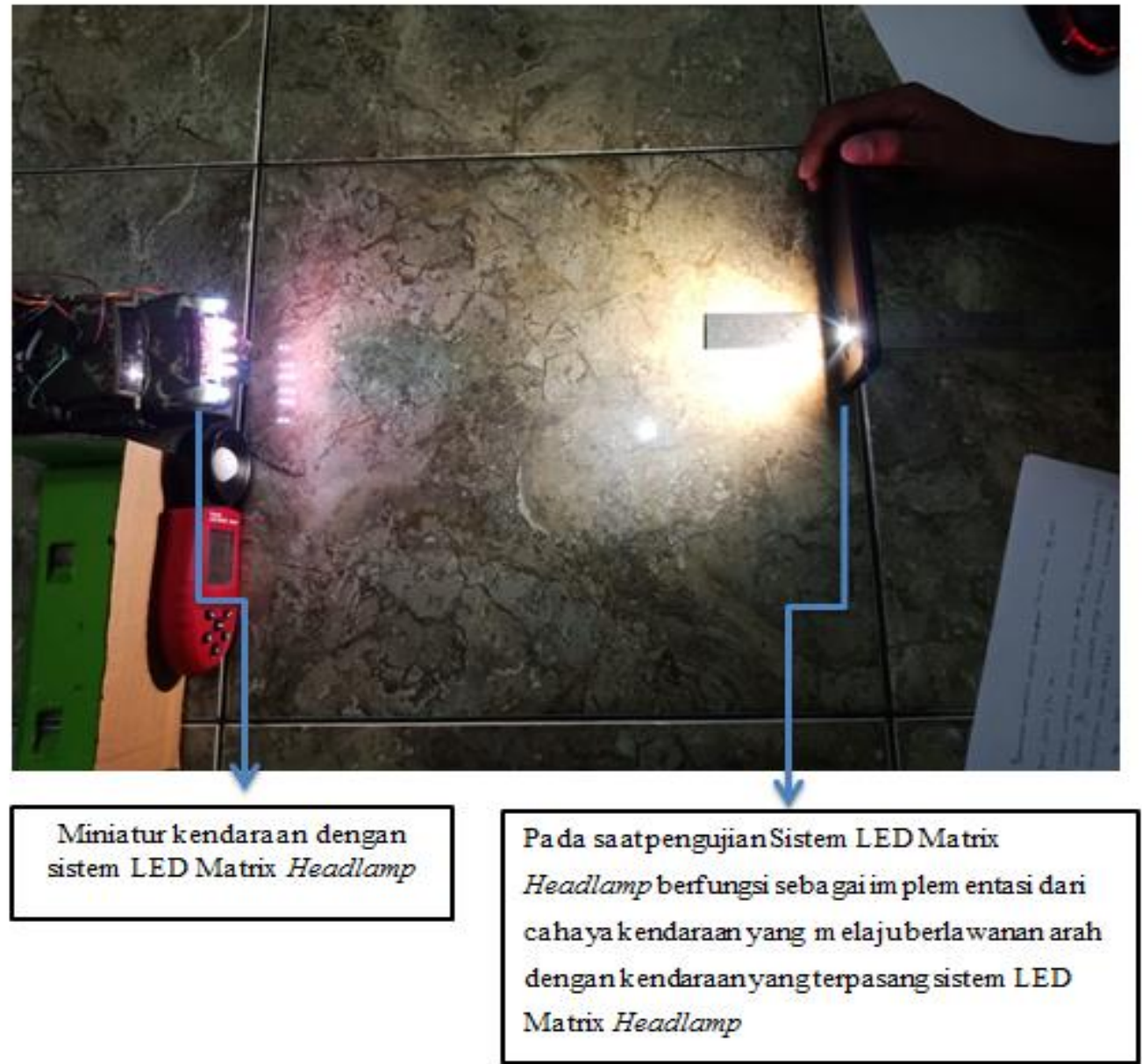

Gambar 4. Rancangan keseluruhan sistem pada saat pengujian alat

Keterangan:

Untuk percobaan ini sebagai masukan cahaya yang diterima oleh sensor hanya menggunakan senter atau pencahayaan dari telepon genggam (senter Hp). Untuk mempermudah dalam pengambilan data karena dalam sebuah senter yang sudah ada sudah terpasang sistem pengaturan cahaya agar bisa memancar ke depan (feletor). Pendorong agar cahaya dapat memancar ke depan dan diterima oleh sensor BH1750. Yang dibutuhkan dalam percobaan ini adalah sebagai berikut,
1. Arduino Uno
2. Sensor BH1750
3. LED warna
4. Rangka Kendaraan dengan sistem LED Matrix Headlamp
5. Baterai 9 volt
6. Senter

\subsection{ALGORITMA}

Setelah perancangan perangkat keras selesai dikerjakan, maka langkah selanjutnya adalah perancangan perangkat lunak (program perintah). Perancangan perangkat lunak menggunakan software Arduino. Hal yang perlu dilakukan terlebih dahulu sebelum membuat program adalah membuat diagram alir (flowchart) sebagai panduan penulisan program. Flowchart dapat dilihat pada Gambar 4. 


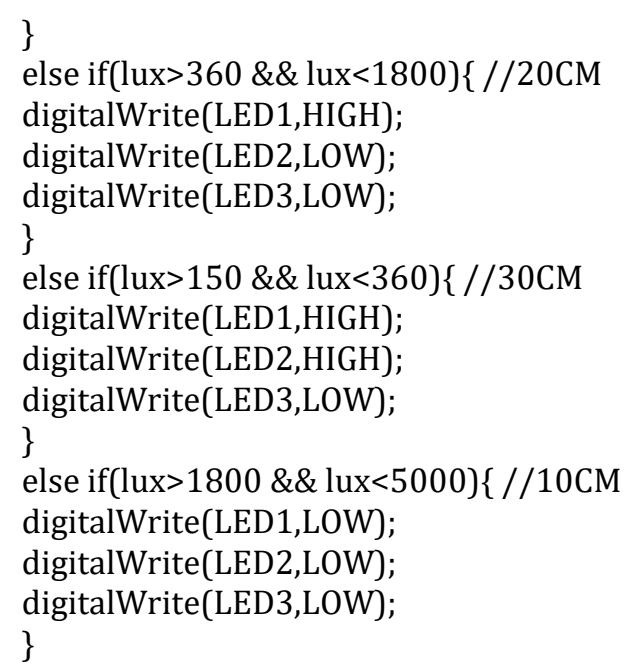

Listing 1. Rancangan keseluruhan sistem pada saat pengujian alat

Listing 1 adalah program yang akan dimasukkan dalam Arduino, yang nantinya dengan pemrograman akan menghasilkan keluaran dengan matinya barisan-barisan LED Matrix Headlamp. Jika nilai masukan yang diterima sensor tidak sesuai dengan pemrograman Arduino Uno, maka akan mengalami error atau keluaran LED tidak hidup.

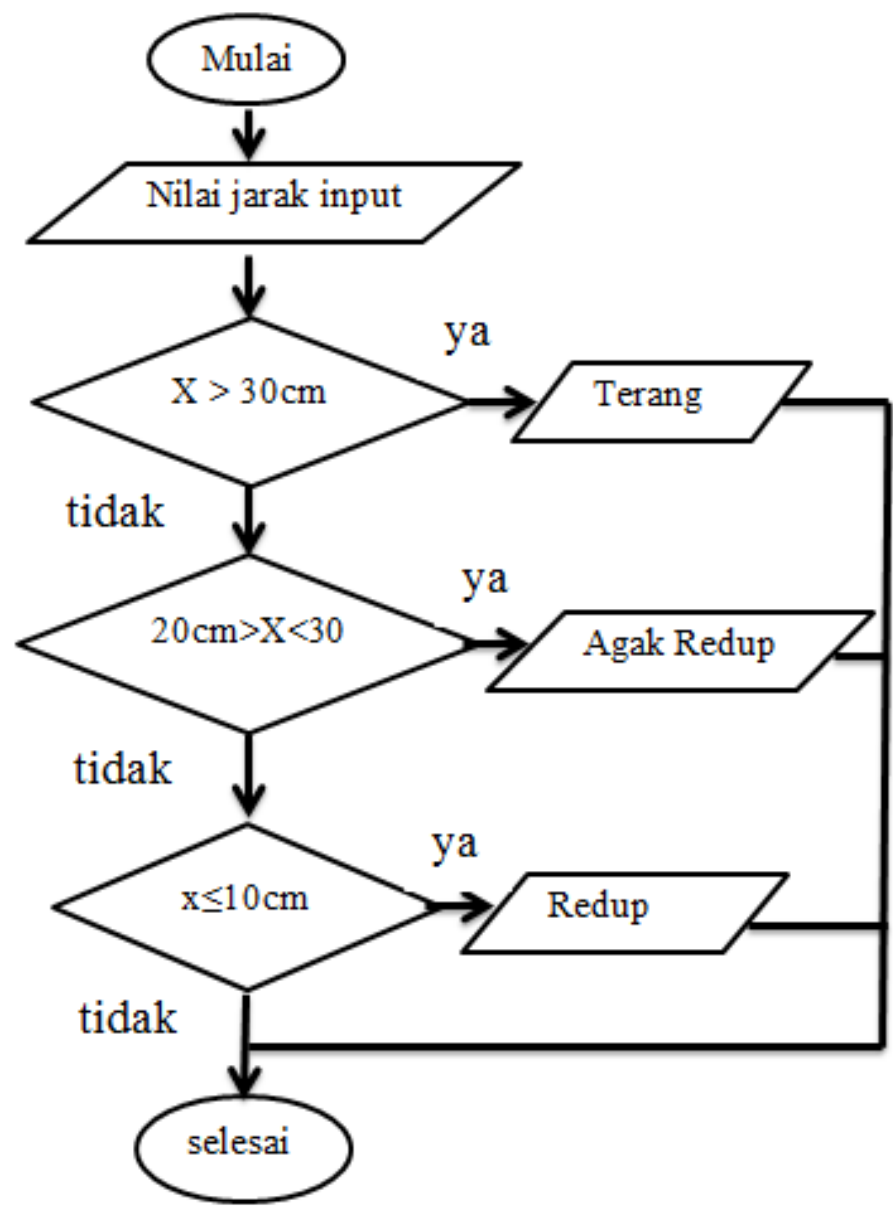

Gambar 4. Digram Alir 
Ketika sistem dihidupkan maka akan menyalakan maka sensor akan langsung membaca kecerahan cahaya yang ada di depan sensor BH1750. Selanjutnya pembacaan tersebut akan digunakan sebagai acuan penentu berapa jarak titik cahaya dengan sensor BH1750. Intensitas yang telah diatur dalam perangkat Arduino adalah sebagai penentu berapa jarak yang berhasil dibaca oleh sensor BH1750. Apabila pembacaan sensor telah berhasil maka dengan program yang telah ada pada Arduino maka akan menghasilkan keluaran LED Matrix akan mematikan beberapa baris LED, yang dalam diagram alir pembagian jarak dikategorikan menjadi 3 (tiga) bagian. Serta baris LED pada percobaan ini juga dibuat ada 3 (tiga) baris LED yang tersusun seri, masingmasing baris.

\section{HASIL DAN PEMBAHASAN}

Setelah melakukan proses perancangan software dan hardware selesai, maka tahap selanjutnya adalah melakukan Analisis data. Analisis data digunakan untuk menganalisis data yang dihasilkan oleh sistem klasifikasi jarak. Data yang dihasilkan yaitu data nilai jarak sumber cahaya dengan sensor BH1750 setelah diolah mikrokontroler. Analisis data yang digunakan untuk sistem secara keseluruhan adalah analisis akurasi dengan mencari rata-rata error dan standar deviasi. Untuk menghitung nilai rata-rata error dan standar deviasi menggunakan persamaan berikut:

Perhitungan yang digunakan untuk menghitung error:

$$
\text { Error }=(\text { Hasil alat ukur LightMeter }- \text { Hasil ukur alat })
$$

Keterangan:

Hasil ukur LightMeter = hasil pengukuran LightMeter secara manual

Hasil terukur alat= hasil pengukura sistem klasifikasi sensor BH1750

Perhitungan yang digunakan untuk menghitung error rata-rata:

$$
\text { Rata }- \text { rata error }=\frac{\text { error } 1+\text { error } 2+\text { error } 3 \ldots \text { errorn }}{\text { jumlah data }}
$$

Keterangan:

Error 1 dst $=$ nilai error pada tiap percobaan

Jumlah data $=$ jumlah keseluruhan data yang diambil

Perhitungan yang digunakan untuk menghitung nilai deviasi:

$$
\mathrm{d}=\text { error }-(\text { error } \text { rata }- \text { rata })
$$

Perhitungan yang digunakan untuk menghitung standar deviasi secara umum adalah sebagai berikut:

$$
\operatorname{Standar} \operatorname{deviasi}(\sigma)=\sqrt{\frac{\mathrm{d} 1+\mathrm{d} 2+\mathrm{d} 3}{\mathrm{n}-1}}
$$

Keterangan:

$$
\begin{aligned}
& \mathrm{s}=\text { standar deviasi } \\
& \mathrm{d}=\text { nilai deviasi setiap percobaan } \\
& \mathrm{n}=\text { banyaknya data percobaan }
\end{aligned}
$$

Berdasarkan analisis dan perancangan sistem yang dijelaskan pada bab III, maka perlu dilakukan pengujian terhadap sistem yang telah direncanakan dan dibuat. Tujuan dari pengujian ini adalah untuk mengetahui apakah sistem yang dibuat sudah sesuai dengan perencanaan atau belum serta untuk mendapatkan data dari sistem tersebut, sehingga dengan diperolehnya data dapat diketahui kinerja dari sistem yang telah dirancang.

Setiap metode pengambilan data dilakukan sebanyak 20 kali percobaan. Kemudian dari data hasil pengujian tersebut akan dihitung persentase keberhasilannya untuk menentukan alat yang dibuat tesebut telah sesuai atau belum dengan tujuan pembuatan. Hasil dari data yang diambil akan dicari persentase error dan 
nilai deviasi atau simpangan hasil pengukuran secara manual atau dengan Lighmeter dibanding dengan hasil dari pengukuran alat ukur sistem klasifikasi pembacaan sensor BH1750.

\subsection{KLASIFIKASI JARAK $X>30 \mathrm{~cm}$}

Pengambilan data pada jarak $X>30 \mathrm{~cm}$ dilakukan sebanyak 20 kali kemudian dari data yang diambil akan dihitung nilai error, rata-rata error dan nilai deviasi. Adapun output LED Matrix Headlamp apabila sensor membaca rangsangan cahaya pada titik ini, sebagai gambar 6.

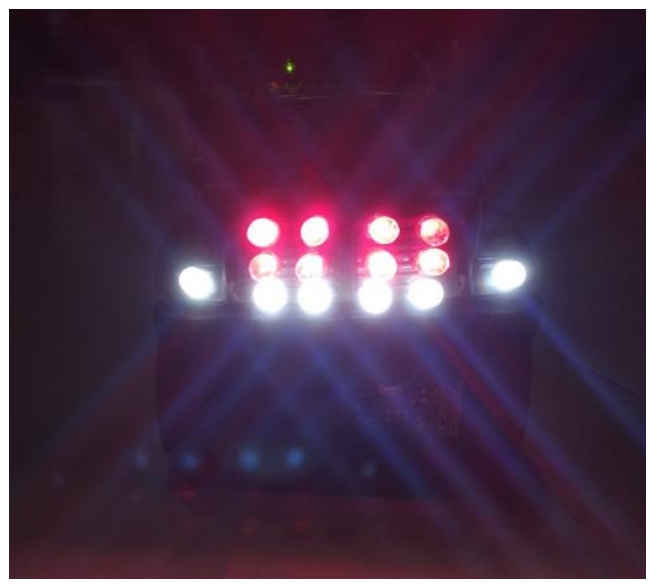

Gambar 6. Tampilan LED Matrix Headlamp pada jarak X>30Cm

Gambar 6 menunjukkan bahwa semua LED dalam keadaan menyala semua, hal tersebut dikarenakan masukan cahaya yang diterima oleh sensor masih belum sesuai dengan jarak yang telah ditetapkan yaitu jarak kurang dari $30 \mathrm{~cm}$. Jadi baik jarak masukan cahaya kendaraan mobil yang berlawanan ada pada jarak $40 \mathrm{~cm}$ atau $50 \mathrm{~cm}$ dan seterusnya maka LED akan terus menyala, selagi belum mencapai jarak kurang dari $30 \mathrm{~cm}$. Pengujian jarak setelah dilakukan 20 kali percobaan maka di dapat hasil seperti ditampilkan pada Tabel 2.

Tabel 1. Data pada jarak $X>30 \mathrm{~cm}$

\begin{tabular}{|c|c|c|c|c|c|}
\hline $\begin{array}{l}\text { Jarak } \\
(\mathrm{cm})\end{array}$ & $\begin{array}{c}\text { Intensitas } \\
\text { Cahaya } \\
\text { Sensor }\end{array}$ & $\begin{array}{c}\text { Intensitas } \\
\text { Cahaya } \\
\text { Lightmeter }\end{array}$ & Error & Deviasi & $\begin{array}{l}\text { Deviasi } \\
\text { kuadrat }\end{array}$ \\
\hline 60 & 124 & 112 & -12 & 41,925 & 1757,705625 \\
\hline 60 & 132 & 120 & -12 & 41,925 & 1757,705625 \\
\hline 60 & 131 & 121 & -10 & 43,925 & 1929,405625 \\
\hline 60 & 127 & 115 & -12 & 41,925 & 1757,705625 \\
\hline 60 & 130 & 118 & -12 & 41,925 & 1757,705625 \\
\hline 60 & 128 & 113 & -15 & 38,925 & 1515,155625 \\
\hline 60 & 130 & 121 & -9 & 44,925 & 2018,255625 \\
\hline 60 & 132 & 120 & -12 & 41,925 & 1757,705625 \\
\hline 60 & 133 & 122 & -11 & 42,925 & 1842,555625 \\
\hline 60 & 134 & 115 & -19 & 34,925 & 1219,755625 \\
\hline 40 & 270 & 208 & -62 & $-8,075$ & 65,205625 \\
\hline 40 & 268 & 207 & -61 & $-7,075$ & 50,055625 \\
\hline 40 & 267 & 201 & -66 & $-12,075$ & 145,805625 \\
\hline 40 & 271 & 205 & -66 & $-12,075$ & 145,805625 \\
\hline 40 & 255 & 202 & -53 & 0,925 & 0,855625 \\
\hline 40 & 262 & 210 & -52 & 1,925 & 3,705625 \\
\hline 40 & 260 & 201 & -59 & $-5,075$ & 25,755625 \\
\hline 40 & 261 & 203 & -58 & $-4,075$ & 16,605625 \\
\hline 40 & 263 & 206 & -57 & $-3,075$ & 9,455625 \\
\hline 40 & 266 & 205 & -61 & $-7,075$ & 50,055625 \\
\hline
\end{tabular}


Tabel 1 merupakan hasil dari pengambilan data masukan cahaya berjarak $40 \mathrm{~cm}$ sebanyak $10 \mathrm{kali}$, dan jarak $60 \mathrm{~cm}$ diambil sebanyak 10 kali. Perbedaan data yang diambil menggunakan Lightmeter dengan data pembacaan sensor alat memiliki perbedaan yang semakin dekat jarak masukan cahaya dengan Lightmeter ataupun sensor BH1750 semakin besar juga nilai intensitas cahayanya.

\subsection{KLASIFIKASI JARAK $12 \mathrm{~cm}>X<30 \mathrm{~cm}$}

Pengambilan data pada jarak $12 \mathrm{~cm}>X<30 \mathrm{~cm}$ dilakukan sebanyak 20 kali kemudian dari data yang diambil akan dihitung nilai error, rata-rata error dan nilai deviasi. Adapun keluaran LED Matrix Headlamp apabila sensor mendapat rangsangan cahaya pada titik ini ditunjukkan pada Gambar 7.

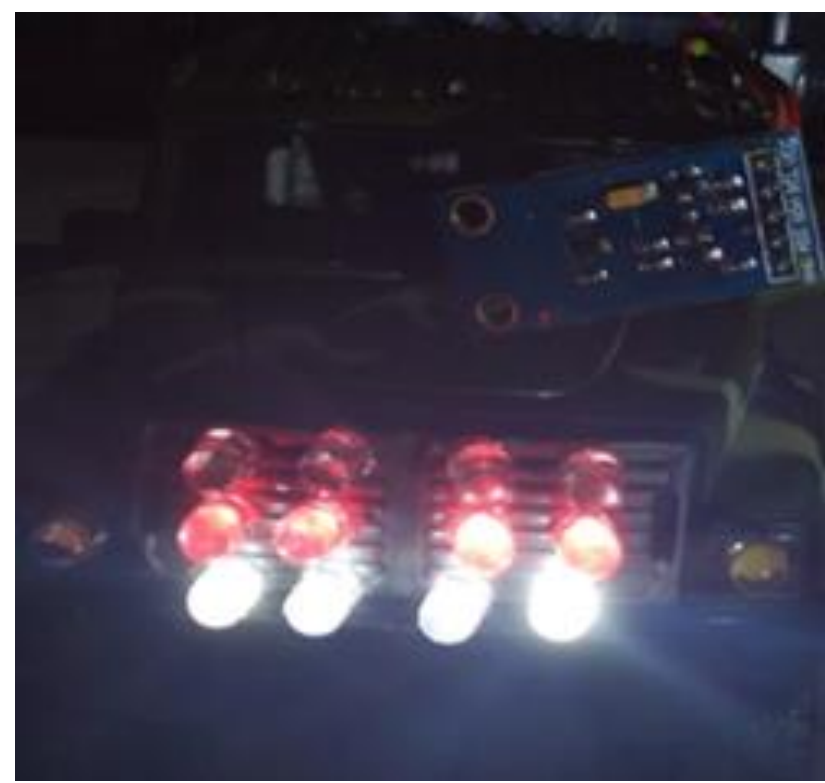

Gambar 7. Tampilan LED Matrix Headlamp pada jarak $12 \mathrm{~cm}>\mathrm{X}<30 \mathrm{~cm}$

Pada jarak lebih dari $12 \mathrm{~cm}$ dan kurang dari $30 \mathrm{~cm}$ bisa dilihat bahwa cahaya pada LED barisan atas mati. Hal tersebut adalah sebagai keluaran dari pembacaan sensor BH1750. Baik untuk jarak $20 \mathrm{~cm}$ atau $29 \mathrm{~cm}$ maka LED barisan paling atas akan tetap mati, karena pada jarak tersebut kurang dari $30 \mathrm{~cm}$ dan lebih dari $12 \mathrm{~cm}$ sesuai yang telah di masukkan pada program Arduino Uno. Pengujian jarak setelah dilakukan 10 kali percobaan maka di dapat hasil seperti ditampilkan pada Tabel 2.

Tabel 2. Data pada jarak $12 \mathrm{~cm}>X<30 \mathrm{~cm}$

\begin{tabular}{cccccc}
\hline $\begin{array}{c}\text { Jarak } \\
(\mathrm{cm})\end{array}$ & $\begin{array}{c}\text { Intensitas } \\
\text { Cahaya } \\
\text { Sensor }\end{array}$ & $\begin{array}{c}\text { Intensitas } \\
\text { Cahaya } \\
\text { Lightmeter }\end{array}$ & Error & Deviasi & $\begin{array}{c}\text { Deviasi } \\
\text { kuadrat }\end{array}$ \\
\hline 20 & 675 & 657 & -18 & 35,925 & 1290,605625 \\
\hline 20 & 667 & 656 & -11 & 42,925 & 1842,555625 \\
\hline 20 & 668 & 659 & -9 & 44,925 & 2018,255625 \\
\hline 20 & 670 & 662 & -8 & 45,925 & 2109,105625 \\
\hline 20 & 665 & 661 & -4 & 49,925 & 2492,505625 \\
\hline 20 & 660 & 665 & 5 & 58,925 & 3472,155625 \\
\hline 20 & 678 & 658 & -20 & 33,925 & 1150,905625 \\
\hline 20 & 681 & 660 & -21 & 32,925 & 1084,055625 \\
\hline 20 & 680 & 665 & -15 & 38,925 & 1515,155625 \\
\hline 20 & 683 & 668 & -15 & 38,925 & 1515,155625 \\
\hline
\end{tabular}


Dari Tabel 2 pengambilan data pada jarak 20cm dilakukan sebanyak 10 kali dengan hasil pembacaan sensor BH1750 relatif lebih besar nilai intensitas cahaya dari pada pembacaan Lightmeter. Nilai error yang ada pada jarak ini apabila dibandingkan dengan data pada jarak $60 \mathrm{~cm}$ dan $40 \mathrm{~cm}$ relatif lebih kecil. Hal tersebut dikarenakan selisih nilai pembacaan sensor alat dengan Lightmeter juga kecil.

\subsection{KLASIFIKASI JARAK $3 \mathrm{~cm}>X<20 \mathrm{~cm}$}

Pengambilan data pada jarak $3 \mathrm{~cm}>\mathrm{X}<20 \mathrm{~cm}$ dilakukan sebanyak 10 kali kemudian dari data yang diambil akan dihitung nilai error, rata-rata error dan nilai deviasi. Adapun output LED Matrix Headlamp apabila sensor membaca rangsangan cahaya pada titik ini, ditunjukkan pada Gambar 8.

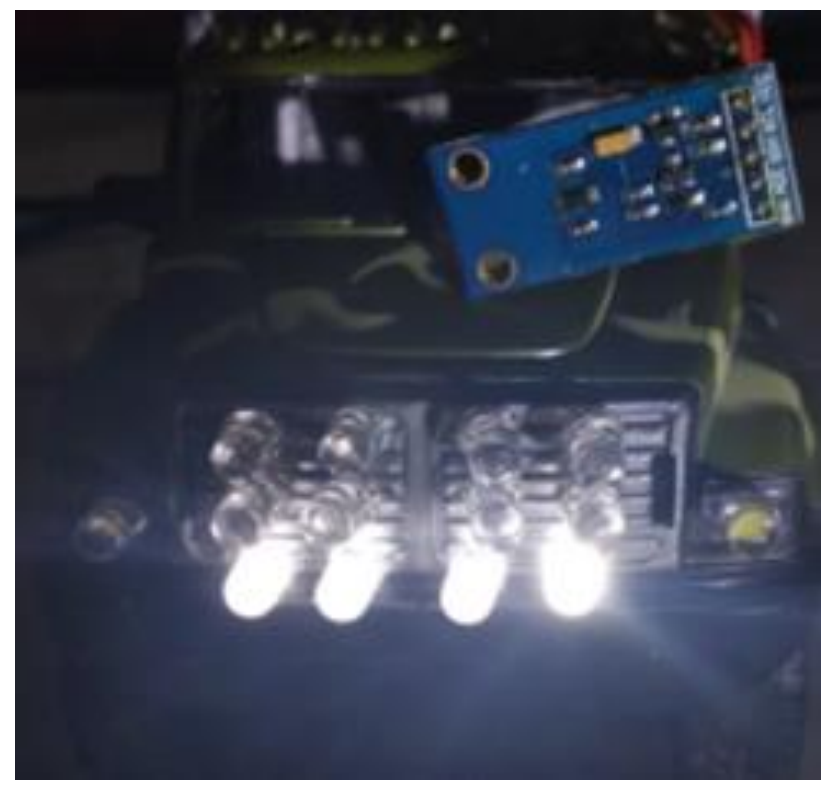

Gambar 8. Tampilan LED Matrix Headlamp pada jarak $3 \mathrm{~cm}>\mathrm{X}<20 \mathrm{~cm}$

Pada gambar 8 terlihat LED barisan paling atas dan tengah mati, hal tersebut dikarenakan jarak masukan cahaya yang diterima oleh sensor berada pada jarak kurang dari $20 \mathrm{~cm}$. Semakin dekat masukan cahaya dari sensor alat maka akan semakin meredup dan pada alat ini untuk meredupkan cahaya yang dipancarkan alat dengan mematikan barisan-barisan dari LED yang terpasang seri di setiap barisnya. Pengujian jarak setelah dilakukan 10 kali percobaan maka di dapat hasil seperti ditampilkan pada Tabel 3.

Tabel 3. Data pada jarak $3 \mathrm{~cm}>X<20 \mathrm{~cm}$

\begin{tabular}{cccccc}
\hline $\begin{array}{c}\text { Jarak } \\
(\mathrm{cm})\end{array}$ & $\begin{array}{c}\text { Intensitas } \\
\text { Cahaya } \\
\text { Sensor }\end{array}$ & $\begin{array}{c}\text { Intensitas } \\
\text { Cahaya } \\
\text { Lightmeter }\end{array}$ & Error & Deviasi & Deviasi kuadrat \\
\hline 10 & 1988 & 1854 & -134 & $-80,075$ & 6412,005625 \\
\hline 10 & 1989 & 1859 & -130 & $-76,075$ & 5787,405625 \\
\hline 10 & 1992 & 1854 & -138 & $-84,075$ & 7068,605625 \\
\hline 10 & 1989 & 1859 & -130 & $-76,075$ & 5787,405625 \\
\hline 10 & 1992 & 1854 & -138 & $-84,075$ & 7068,605625 \\
\hline 10 & 1972 & 1855 & -117 & $-63,075$ & 3978,455625 \\
\hline 10 & 1994 & 1851 & -143 & $-89,075$ & 7934,355625 \\
\hline 10 & 1992 & 1852 & -140 & $-86,075$ & 7408,905625 \\
\hline 10 & 1995 & 1848 & -147 & $-93,075$ & 8662,955625 \\
\hline 10 & 1982 & 1849 & -133 & $-79,075$ & 6252,855625 \\
\hline
\end{tabular}

Tabel 3 merupakan pengambilan data berdasarkan input yang diterima sensor dengan jarak $10 \mathrm{~cm}$ 
sebanyak 10 kali. Dari data yang didapat nilai error terlihat besar, dikarenakan perbedaan nilai baca intensitas cahaya sensor dengan Lightmeter mempunyai perbedaan nilai yang besar. Perbedaan nilai tersebut disebabkan karena peletakan sensor BH1750 dan Lightmeter memiliki perbedaan serta tingkat sensitivitas sensor alat dengan Lightmeter mempunyai perbedaan. Dari ketiga pengambilan data tersebut dapat disimpulkan error ratarata, varian, serta standar deviasinya. Serta mendapatkan hasil sebuah tabel, dari data jarak $10 \mathrm{~cm}$ sampai dengan $40 \mathrm{~cm}$.

Tebel 4. Perhitungan error rata-rata, varian, dan standar deviasi

\begin{tabular}{cc}
\hline Rata-Rata error & $-53,925$ \\
\hline Varian & 2663,696622 \\
\hline Standar Deviasi & 51,6110126 \\
\hline
\end{tabular}

Penentuan error rata-rata, varian, standar deviasi yang didapat pada tabel 4 merupakan dari keseluruhan pengambilan data dari jarak $60 \mathrm{~cm}$ sebanyak $10 \mathrm{kali}, 40 \mathrm{~cm}$ sebanyak $10 \mathrm{kali}, 20 \mathrm{~cm}$ sebanyak $10 \mathrm{kali}$, dan $10 \mathrm{~cm}$ sebanyak 10 kali. Nilai error rata-rata yang diperoleh dari keseluruhan pengambilan data percobaan ini masih cukup besar yaitu 53,925. Besarnya error yang didapat dipengaruhi oleh perbedaan nilai baca sensor alat dengan pembacaan secara manual menggunakan Lighmeter. Walaupun nilai error rata-rata yang diperoleh masih cukup besar, tatapi percobaan pada kali ini bisa dikatakan sukses karena output yang dikeluarkan LED sesuai dengan yang diinginkan.

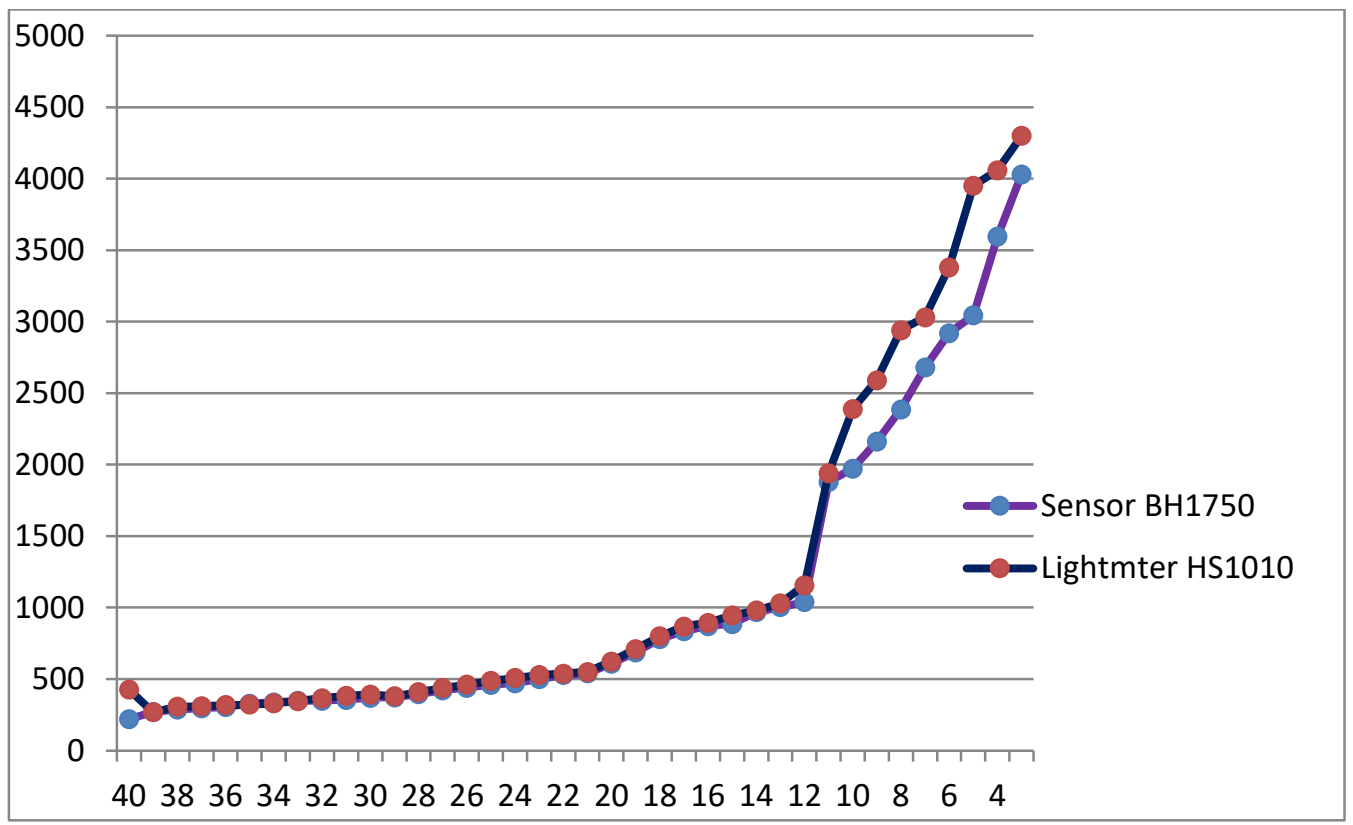

Gambar 9. Grafik perbandingan data manual dengan Sensor alat

Grafik pada Gambar 9 merupakan grafik yang didapat dari pengambilan nilai pembacaan sensor alat dengan Lightmeter pada jarak $3 \mathrm{~cm}$ sampai $40 \mathrm{~cm}$. Serta dapat dilihat bahwa perbedaan garis pada grafik di bawah ini mulai terlihat jauh berbeda pada jarak di bawah $10 \mathrm{~cm}$. Dikarenakan sensitivitas antara sensor yang terpasang pada alat dan Lightmeter pembacaan manual mempunyai perbedaan.

\section{KESIMPULAN}

Perlunya diperhatikan peletakan sensor BH1750 pada kendaraan, pada alat ini menggunakan kendaraan mainan untuk mempermudah dalam pengujian serta pengambilan data. Peletakan sensor perlu diperhatikan supaya lampu utama pada kendaraan atau mobil mainan tidak mempengaruhi nilai baca sensor BH1750 dengan kecerahan cahaya pada kendaraan yang ada pada arah berlawanan. Pengaruhnya adalah penentuan nilai rentan pembacaan sensor BH1750 yang di masukkan dalam pemrograman Arduino Uno.

\section{UCAPAN TERIMA KASIH}

Terima kasih tak lupa penulis ucapkan kepada editor dan reviewer atas semua atas saran dan masukkan serta kepada semua pihak yang terkait dalam penyelesaian jurnal ini. Semoga kebaikan yang telah diberikan kepada 
penulis dapat menjadi amal ibadah dengan balasan pahala dari Allah SWT. Penulis mengharapkan agar tugas akhir ini dapat dimanfaatkan dengan sebaik-baiknya guna menambah ilmu pengetahuan khususnya bagi para pembaca pada umumnya.

\section{REFERENSI}

[1] Allif Maulana, Rizal Maulana, Hurriyatul F (2018) Perancangan dan Implementasi Headlamp Pada Sepeda Motor Sebagai Pengatur Jarak Aman Pancaran Cahaya Dengan Menggunakan Sistem LED Matrix. Universitas Brawijaya.

[2] D. Prihatmoko, "Perancangan Dan Implementasi Pengontrol Suhu Ruangan Berbasis Mikrokontroller Arduino Uno," Simetris J. Tek. Mesin, Elektro dan Ilmu Komput., vol. 7, no. 1, p. 117, 2017.

[3] Benny Julia (2013) Perancangan Display LED Dot Matrix Menggunakan Mikrokontroler ATmega32. Universitas Tanjungpura.

[4] Ristekdikti. (2018). Buku PAnduan Kontes Robot Sepakbola Indonesia Beroda (KRSBI Beroda). Direktorat Kemahasiswaan Direktorat Jenderal Pembelajaran Dan Kemahasiswaan Kementerian Riset, Teknologi Dan Pendidikan Tinggi Republik Indonesia.

[5] Naa, C.F., Padang, E., Handayani, Y,S., Hendro (2015). Sistem Monitoring dan Kontrol Rumah Kaca berbasis Arduino, LabView dan Antarmuka Web. Laporan Penelitian tidak di publikasikan. Bandung: Universitas Katolik Parahyangan.

[6] Respatia, F.F.I.W.S (2016). Sistem Akuisisi Data Kincir Angin Propler Berbahan Kayu. Laporan Penelitian tidak di publikasikan. Yogyakarta:Universitas Sanata Dharma.

[7] R. Birdayansyah, N. Sudjarwanto, and O. Zebua, "Pengendalian Kecepatan Motor DC Menggunakan Perintah Suara Berbasis Mikrokontroler Arduino," J. Rekayasa dan Teknol. Elektro, vol. 9, no. 2, pp. 97-107, 2015.

[8] P. Prasetyawan, Y. Ferdianto, S. Ahdan, and F. Trisnawati, "Pengendali Lengan Robot Dengan Mikrokontroler Arduino Berbasis Smartphone,” J. Tek. Elektro ITP, vol. 7, no. 2, pp. 104-109, 2018.

[9] Saptaji (2015) Mengukur intensitas cahaya dengan ldr dan arduino. Universitas Ahmad Dahlan Yogyakarta

[10] Anindya, C., Fuada, S., Firmansyah, S., \& Lestari, D. (2014). Rancang Bangun Prototype Robot Pipe Tracking dengan Electric Nose Technology sebagai Detektor Ke-bocoran.Program Kreativitas Maha-siswa-Karsa Cipta.Malang: Jurusan Pen-didikan Teknik Elektro FT UNM.

\section{BIOGRAFI PENULIS}
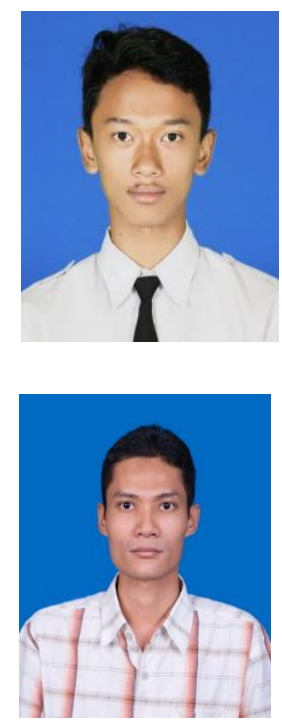

Jatmiko Tri Waluyo

Penulis 1 adalah mahasiswa program studi teknik elektro Universitas Ahmad Dahlan.

\section{Nuryono Satya Widodo}

Penulis 2 adalah dosen program studi teknik elektro Universitas Ahmad Dahlan. 